\title{
Anterior lumbar compared to oblique lumbar interbody approaches for multilevel fusions to the sacrum in adults with spinal deformity and degeneration
}

\author{
Zhuo Xi, MD, ${ }^{1,4}$ Dean Chou, MD, ${ }^{1}$ Praveen V. Mummaneni, MD, ${ }^{1}$ Huibing Ruan, MD, ${ }^{1}$ \\ Charles Eichler, MD, ${ }^{2}$ Chih-Chang Chang, MD, ${ }^{1}$ and Shane Burch, MD ${ }^{3}$ \\ 1Department of Neurological Surgery, ${ }^{2}$ Division of Vascular Surgery, and ${ }^{3}$ Department of Orthopedic Surgery, University of \\ California, San Francisco, California; and ${ }^{2}$ Department of Neurosurgery, Shengjing Hospital of China Medical University, \\ Shenyang, Liaoning, China
}

\begin{abstract}
OBJECTIVE In adult spinal deformity and degenerative conditions of the spine, interbody fusion to the sacrum often is performed to enhance arthrodesis, induce lordosis, and alleviate stenosis. Anterior lumbar interbody fusion (ALIF) has traditionally been performed, but minimally invasive oblique lumbar interbody fusion (OLIF) may or may not cause less morbidity because less retraction of the abdominal viscera is required. The authors evaluated whether there was a difference between the results of ALIF and OLIF in multilevel anterior or lateral interbody fusion to the sacrum.
\end{abstract}

METHODS Patients from 2013 to 2018 who underwent multilevel ALIF or OLIF to the sacrum were retrospectively studied. Inclusion criteria were adult spinal deformity or degenerative pathology and multilevel ALIF or OLIF to the sacrum. Demographic, implant, perioperative, and radiographic variables were collected. Statistical calculations were performed for significant differences.

RESULTS Data from a total of 127 patients were analyzed (66 OLIF patients and 61 ALIF patients). The mean follow-up times were 27.21 (ALIF) and 24.11 (OLIF) months. The mean surgical time was 251.48 minutes for ALIF patients and 234.48 minutes for OLIF patients $(p=0.154)$. The mean hospital stay was 7.79 days for ALIF patients and 7.02 days for OLIF patients $(p=0.159)$. The mean time to being able to eat solid food was 4.03 days for ALIF patients and 1.30 days for OLIF patients $(p<0.001)$. After excluding patients who had undergone L5-S1 posterior column osteotomy, 54 ALIF patients and 41 OLIF patients were analyzed for L5-S1 radiographic changes. The mean cage height was $14.94 \mathrm{~mm}$ for ALIF patients and $13.56 \mathrm{~mm}$ for OLIF patients ( $p=0.001)$, and the mean cage lordosis was $15.87^{\circ}$ in the ALIF group and $16.81^{\circ}$ in the OLIF group ( $p=0.278$ ). The mean increases in anterior disc height were $7.34 \mathrm{~mm}$ and $4.72 \mathrm{~mm}$ for the ALIF and OLIF groups, respectively $(p=0.001)$, and the mean increases in posterior disc height were $3.35 \mathrm{~mm}$ and $1.24 \mathrm{~mm}(p<0.001)$, respectively. The mean change in L5-S1 lordosis was $4.33^{\circ}$ for ALIF patients and $4.59^{\circ}$ for OLIF patients $(p=0.829)$.

CONCLUSIONS Patients who underwent multilevel OLIF and ALIF to the sacrum had comparable operative times. OLIF was associated with a quicker ileus recovery and less blood loss. At L5-S1, ALIF allowed larger cages to be placed, resulting in a greater disc height change, but there was no significant difference in L5-S1 segmental lordosis. https://thejns.org/doi/abs/10.3171/2020.4.SPINE20198

KEYWORDS oblique lumbar; anterior lumbar; interbody fusion; ALIF; CCI; Charlson Comorbidity Index; OLIF; prepsoas; degenerative; deformity

I $\mathrm{N}$ long fusions to the sacrum for adult deformity or degenerative lumbar conditions, interbody fusion is often used to enhance arthrodesis, induce lordosis, and alleviate foraminal stenosis. ${ }^{1}$ In the treatment of multilevel lumbar pathology, anterior lumbar interbody fusion (ALIF) has been shown to have advantages over trans- foraminal lumbar interbody fusion (TLIF) with regard to improving lordosis and disc height. ${ }^{2-4}$ However, there can be significant approach-related morbidity caused by the manipulation of the great vessels and the abdominal viscera.$^{5,6}$ Thus, minimally invasive surgical approaches to access the anterior lumbar spine have been developed-

ABBREVIATIONS ALIF = anterior lumbar interbody fusion; CCI = Charlson Comorbidity Index; LLIF = lateral lumbar interbody fusion; OLIF = oblique lumbar interbody fusion; $\mathrm{PCO}$ = posterior column osteotomy; TLIF = transforaminal lumbar interbody fusion.

SUBMITTED February 13, 2020. ACCEPTED April 9, 2020.

INCLUDE WHEN CITING Published online June 12, 2020; DOI: 10.3171/2020.4.SPINE20198. 
most specifically, lateral lumbar interbody fusion (LLIF). Although LLIF is a good option to access lumbar pathology from L2 to L5, L5-S1 often is degenerated and needs to be included in the fusion construct. However, performing the LLIF from L2 to L5 and then performing an ALIF at L5-S1 requires repositioning the patient, repreparation and draping of the patient, a separate skin incision, and mobilization of the abdominal viscera. ${ }^{7,8}$ Alternatively, an L5-S1 TLIF can be performed, but this may not be ideal if there is dorsal scar tissue, a clinical need for more lordosis than a TLIF can achieve, or pseudarthrosis requiring an anterior approach.

Oblique lumbar interbody fusion (OLIF), also known as an the antepsoas or prepsoas approach, is one type of LLIF, and the OLIF approach affords the ability to include the L5-S1 segment, unlike traditional LLIF, which historically has been limited to L5 or higher. However, adding an L5-S1 OLIF onto an L2-5 OLIF requires a separate skin incision, separate retractors, the assistance of a vascular surgeon, and different types of cages. One advantage of multilevel OLIF is that it does not require repositioning of the patient or repreparation and re-draping. ${ }^{9}$ Although the L5-S1 OLIF can be done in the same position as an L2-5 OLIF, it is unclear if OLIF at L5-S1 is as good at restoring intervertebral disc height and lordosis as ALIF.10,11 It is also unclear if making two separate small incisions yields less morbidity than simply performing a multilevel ALIF through a single incision. Thus, in the current study, we compared multilevel ALIF and multilevel OLIF to the sacrum in patients with adult deformity and degenerative disease to evaluate perioperative and radiographic parameters.

\section{Methods}

We performed a retrospective review of patients undergoing multilevel ALIF and OLIF to the sacrum at the University of California, San Francisco, from 2013 to 2018 by 3 spine surgeons and 1 vascular surgeon. The study was approved by the institutional review board, and patient consent was not necessary for this retrospective research. The inclusion criteria included patients with adult degenerative scoliosis, degenerative lumbar conditions, age $\geq 18$ years, a minimum 1-year follow-up, and multilevel lumbar interbody fusion (ALIF or OLIF), with all patients also undergoing L5-S1 ALIF or OLIF in the same surgical setting. Patients with tumors, infection, inadequate imaging, or trauma were excluded. Data collected were demographic variables, Charlson Comorbidity Index (CCI), operative time, blood loss, transfusion, time to solid food intake, length of hospital stay, and fusion rates. Operative times were calculated as skin-to-skin surgical times during the ALIF and OLIF portion, not the induction, patient positioning, or posterior surgery; blood loss and transfusions were analyzed in cases of anterior surgery only. Fusion rates were determined using either CT scans or radiographs, and arthrodesis was classified as fusion, no fusion, and indeterminate. Fusion rates were evaluated at each interbody graft level, and overall OLIF and ALIF fusion rates were compared. We also analyzed the radiographic changes at L5-S1 given the relative novelty of the L5-S1 OLIF. Although patients with posterior column osteotomies (PCOs) at L5-S1 were included in the clinical analysis of approach-related morbidity, they were excluded from the radiographic analysis because of the osteotomy. Radiographic parameters such as L5-S1 disc height and segmental lordosis were measured on preoperative and immediate postoperative lateral radiographs. All measurements were performed by 2 attending spinal neurosurgeons and 1 orthopedic spine surgeon. Complications related to the anterior or oblique approach were collected. All patients were immediately placed on a clear liquid diet postoperatively, and once patients had a bowel movement, they were advanced to solid food. Ileus was defined as severe abdominal distension on clinical examination, dilated loops of bowel observed on upright abdominal radiographs, no flatus whatsoever, extreme abdominal discomfort precluding ambulation, and requirement of a hospitalist consultation confirming the diagnosis of ileus.

Categorical variables are presented as numbers, and continuous variables are presented as means with SDs. The Kolmogorov-Smirnov test was used to assess for normal distribution of the findings, and independent sample t-tests and chi-square tests were used to evaluate differences between ALIF and OLIF variables. Values of $p<$ 0.05 were considered statistically significant, and all statistical analyses were performed using SPSS version 17.0.

\section{Surgical Technique of Multilevel ALIF to the Sacrum}

ALIFs were performed via anterior retroperitoneal approaches with a vascular surgeon. A lower paramedian incision was created and carried down to the anterior rectus sheath, which was incised longitudinally. The rectus muscle was mobilized laterally, the posterior rectus sheath incised, and the retroperitoneal space established. The peritoneum was then widely mobilized toward the patient's contralateral side. Dissection was carried up along the psoas muscle from the iliac artery up onto the aorta. Exposure of the L5-S1 interspace was done by working within the bifurcation of the great vessels. The middle sacral vessels were divided, the prevertebral space was established, and wide exposure of the L5-S1 disc was obtained. The recurrent iliolumbar vein was then divided to mobilize the iliac vein for the L4-5 disc space and higher. At this point, the spinal level was confirmed fluoroscopically, and ALIF was performed in the traditional manner ${ }^{12,13}$ (Figs. 1 and 2).

\section{Surgical Technique of Multilevel OLIF to the Sacrum}

The patient was placed into the right lateral decubitus position (OLIF can only be performed from the left side in order to avoid the vena cava). L2-5 OLIF was performed before or after the L5-S1 portion of the procedure, depending on the availability of the vascular surgeon. For L5-S1, the disc space was marked out using fluoroscopy, and a horizontal line relative to the L5-S1 disc space was drawn on the skin. The incision was drawn approximately 2 finger breadths anterior to the iliac crest (Fig. 3). After skin incision, the dissection was then carried through the external oblique, internal oblique, and transversus abdominis, which were all bluntly separated in the direction of their fibers. The preperitoneal space was established, 

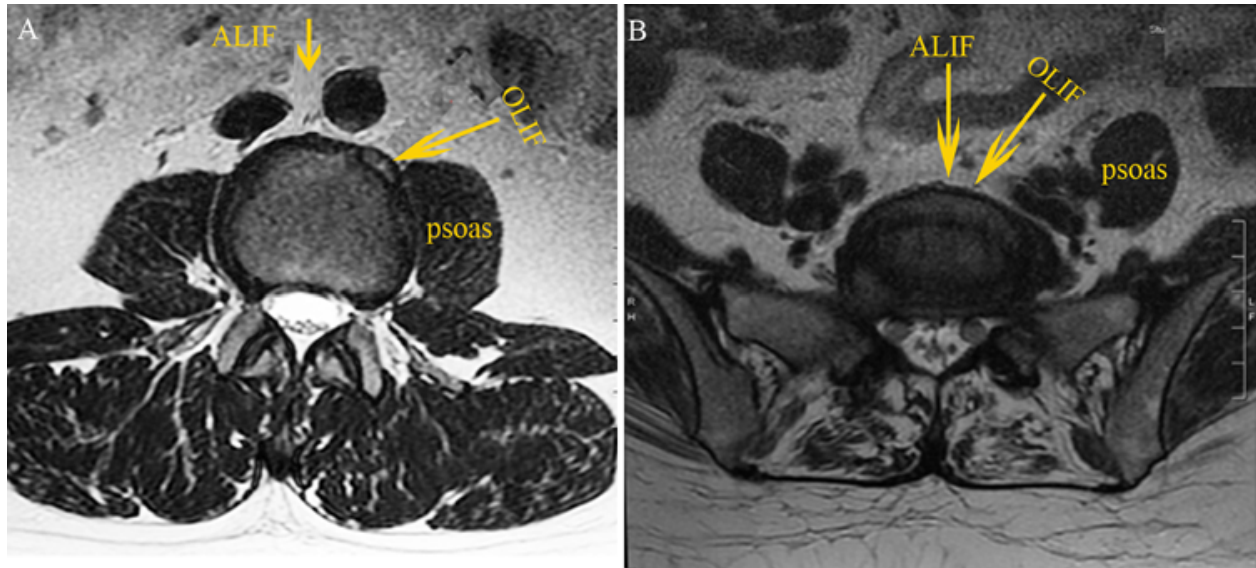

FIG. 1. Illustration comparing OLIF and ALIF at L2-5 (A) and at L5-S1 (B). Figure is available in color online only.

and using blunt dissection, the peritoneum was mobilized toward the patient's right. Dissection was then carried out between the right and left iliac veins, the middle sacral vessels were divided, the prevertebral space was established, and exposure of the L5-S1 disc was obtained. The procedure was performed with the use of C-arm fluoroscopy.

For the L2-5 portion, a percutaneous reference arc was placed into the left iliac crest through a separate stab incision. An intraoperative CT scan was obtained (O-arm, Medtronic), and StealthStation navigation (Medtronic) was registered with the acquired images. A skin incision was made in an oblique fashion approximately $5 \mathrm{~cm}$ anterior to the lumbar vertebrae. The dissection was carried down through the external oblique, internal oblique, and transversus abdominis until retroperitoneal fat was identified. The navigational probe was then docked at the appropriate disc space anterior to the psoas. Dilators were placed, and the minimally invasive surgical retractor was placed. The lateral interbody fusion was carried out in the standard manner, described elsewhere in detail ${ }^{11,14,15}$ (Figs. 1 and 4).

The decision as to whether multilevel ALIF or OLIF would be performed was based on patient anatomy. For instance, if the patient had a left-sided concave scoliosis that needed L2-3 addressed, then a multilevel OLIF was chosen because of the ability to correct the scoliosis and address L2-3. If, however, the patient had a low L4-5 below the iliac crest, or if the patient only needed L4-S1 fused, the patient may have instead undergone an ALIF.

\section{Results \\ Clinical Variables}

A total of 127 patients (51 males, 76 females) met the inclusion criteria, with 66 OLIF patients and 61 ALIF patients (Table 1). The range of follow-up was 12-60 months. With the Kolmogorov-Smirnov test, the data followed a normal distribution except for blood loss.

The mean age was $63.73 \pm 10.80$ years. There were no significant differences between OLIF and ALIF patient ages $(p=0.142)$ or sex $(p=0.364)$. The mean CCI score for ALIF was $2.64 \pm 1.95$ and that for OLIF was $2.58 \pm 1.67$ $(\mathrm{p}=0.845)$. The mean follow-up was $27.21 \pm 6.77$ months for ALIF and $24.11 \pm 6.93$ months for OLIF $(p=0.112)$. For staging, 7 patients underwent anterior stand-alone fusion only, 58 patients underwent anterior-posterior fusion in 1 day, and 62 patients underwent anterior and poste-
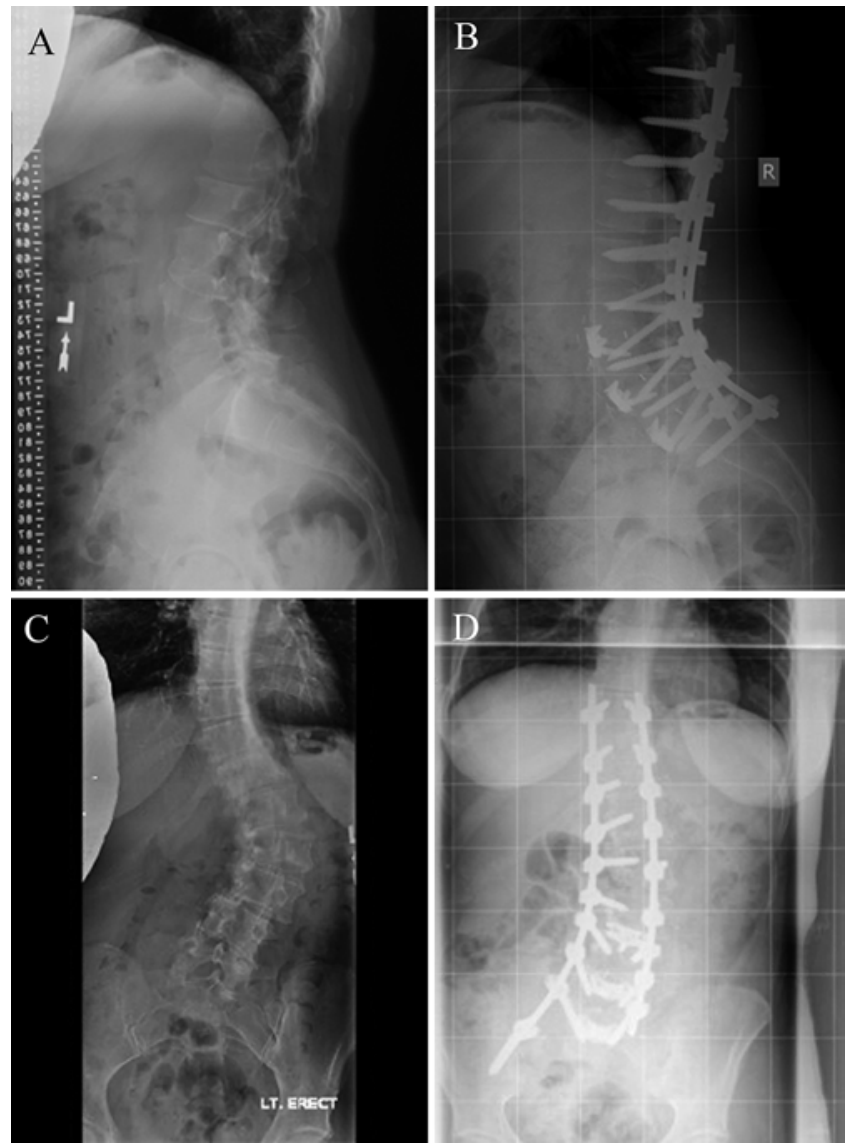

FIG. 2. Lateral and anterior-posterior radiographs showing the change in height and lordosis at L5-S1 before (A and C) and after (B and D) ALIF surgery. 

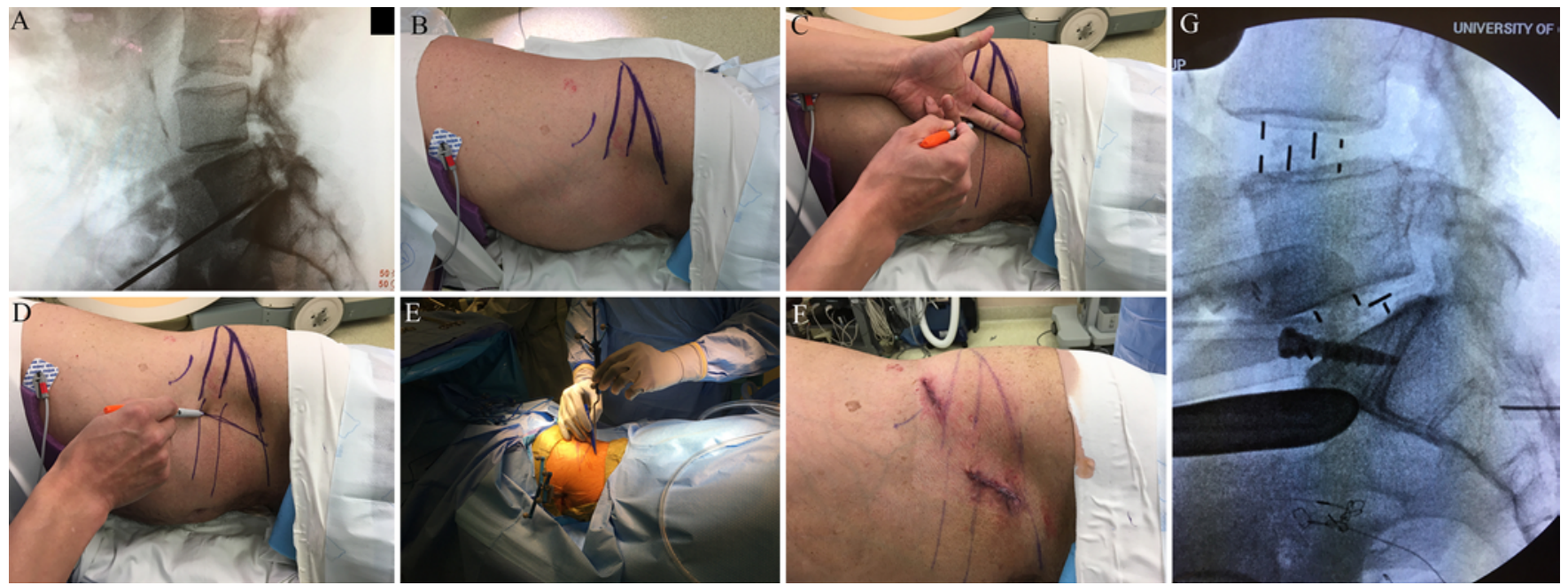

FIG. 3. Images showing the incision planning and the cage position of the L4-S1 OLIF. A: Marking the angle of the L5-S1 disc on the skin. B: A line horizontal to the spine is subsequently drawn on the skin. $C$ and $D: A$ vertical incision is drawn 2 fingerbreadths anterior to the iliac crest. E: A skin incision is made in an oblique fashion approximately $5 \mathrm{~cm}$ anterior to the L4 and L5 lumbar vertebrae using navigation. F: The positional relationship between L4-5 and L5-S1 skin incisions. G: Intraoperative C-arm fluoroscopy demonstrating the cage positions. Figure is available in color online only.

rior fusion on 2 separate days. There were no significant differences between OLIF and ALIF patients $(\mathrm{p}=0.237)$ in terms of staged versus same-day cases. However, the mean days between anterior and posterior surgeries were
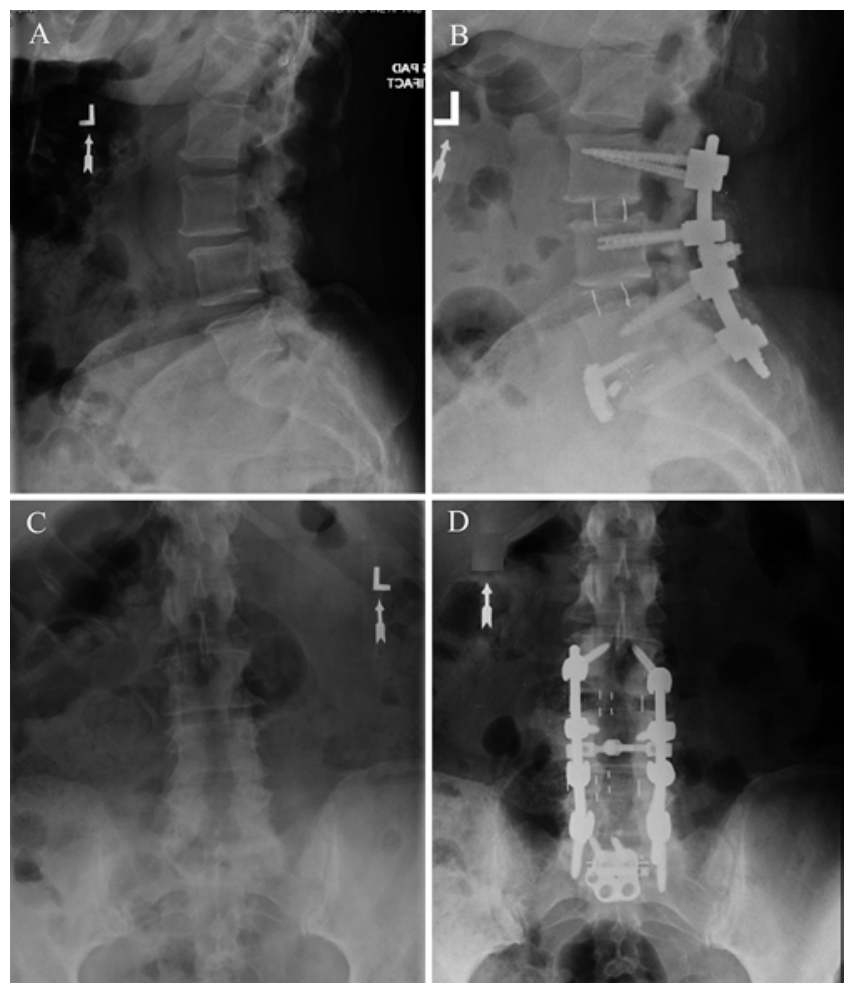

FIG. 4. Lateral and anterior-posterior radiographs showing the change in height and lordosis at L5-S1 before (A and C) and after (B and D) L5-S1 OLIF.
$4.22 \pm 3.07$ days for ALIF and $1.93 \pm 1.66$ days for OLIF $(\mathrm{p}=0.002)$. Sixty-five patients had anterior fusion from L4 to S1 (34 ALIF, 31 OLIF), 35 patients had anterior fusion from L3 to S1 (23 ALIF, 12 OLIF), and 27 patients had L2-S1 anterior fusion (4 ALIF, 23 OLIF). The mean surgical times were $251.48 \pm 67.04$ minutes and $234.48 \pm$ 66.51 minutes for ALIF and OLIF ( $\mathrm{p}=0.154)$, respectively. We used a nonparametric test to analyze blood loss, and the mean blood losses for ALIF and OLIF were 387.92 \pm $310.40 \mathrm{ml}$ and $90.91 \pm 98.12 \mathrm{ml}(\mathrm{p}<0.001)$, respectively. The average time to solid food intake was $4.03 \pm 2.55$ days for ALIF and $1.3 \pm 1.64$ days for OLIF $(p<0.001)$. The mean hospital stay was $7.79 \pm 3.46$ days for ALIF and 7.02 \pm 2.65 days for OLIF $(\mathrm{p}=0.159)$. The radiographic interbody fusion rate was $80.4 \%$ (123/153 levels) for ALIF and $76.3 \%$ (145/190 levels) for OLIF, without a significant difference $(p=0.364)$. Posterior arthrodesis was not analyzed. Complications are shown in Table 1, and diagnoses are shown in Supplemental Table 1.

\section{Radiographic Analysis in Patients Without PCOs at L5-S1}

As shown in Table 2, there were 7 ALIF and 25 OLIF patients who underwent L5-S1 PCOs, leaving 54 ALIF and 41 OLIF patients for radiographic analysis at L5-S1. In these 95 patients, the mean ALIF cage height was 14.94 $\pm 1.56 \mathrm{~mm}$ for ALIF and $13.56 \pm 2.11 \mathrm{~mm}$ for OLIF $(\mathrm{p}$ $=0.001)$. The mean cage lordosis was $15.87^{\circ} \pm 4.23^{\circ}$ for ALIF and $16.81^{\circ} \pm 3.71^{\circ}$ for OLIF $(p=0.278)$. The mean preoperative anterior disc height was $11.53 \pm 3.46 \mathrm{~mm}$ for ALIF and $12.45 \pm 4.08 \mathrm{~mm}$ for OLIF ( $\mathrm{p}=0.234)$. The mean postoperative anterior disc height was $18.87 \pm 3.82$ $\mathrm{mm}$ for ALIF and $17.17 \pm 4.22 \mathrm{~mm}$ for OLIF $(\mathrm{p}=0.043)$. The mean increase in anterior disc height was $7.34 \pm 3.84$ $\mathrm{mm}$ for ALIF and $4.72 \pm 3.41 \mathrm{~mm}$ for OLIF $(\mathrm{p}=0.001)$. The mean preoperative posterior disc height was $5.44 \pm$ $2.07 \mathrm{~mm}$ for ALIF and $5.93 \pm 1.95 \mathrm{~mm}$ for OLIF $(\mathrm{p}=$ 
TABLE 1. Clinical information and perioperative factors

\begin{tabular}{|c|c|c|c|c|}
\hline Variable & Total $(n=127)$ & ALIF $(n=61)$ & OLIF $(n=66)$ & p Value \\
\hline Age (yrs) & $63.73 \pm 10.80$ & $63.57 \pm 9.83$ & $63.88 \pm 11.69$ & 0.142 \\
\hline Sex & & & & 0.364 \\
\hline Male & 51 & 27 & 24 & \\
\hline Female & 76 & 34 & 42 & \\
\hline $\mathrm{CCl}$ score & $2.61 \pm 1.81$ & $2.64 \pm 1.95$ & $2.58 \pm 1.67$ & 0.845 \\
\hline Follow-up time & $25.63 \pm 5.88$ & $27.21 \pm 6.77$ & $24.11 \pm 6.93$ & 0.112 \\
\hline Surgical approach & & & & 0.237 \\
\hline Anterior only & 7 & 5 & 2 & \\
\hline Anterior + posterior in 1 day & 58 & 24 & 34 & \\
\hline Anterior + posterior in 2 days & 62 & 32 & 30 & \\
\hline Days btwn anterior \& posterior op & $3.11 \pm 3.04$ & $4.22 \pm 3.07$ & $1.93 \pm 1.66$ & 0.002 \\
\hline Anterior levels & & & & $<0.001$ \\
\hline L5-S1 & 0 & 0 & 0 & \\
\hline L4-S1 & 65 & 34 & 31 & \\
\hline L3-S1 & 35 & 23 & 12 & \\
\hline L2-S1 & 27 & 4 & 23 & \\
\hline$>4$ levels & 0 & 0 & 0 & \\
\hline Posterior levels & & & & 0.712 \\
\hline L5-S1 & 2 & 0 & 2 & \\
\hline L4-S1 & 40 & 18 & 22 & \\
\hline L3-S1 & 25 & 12 & 13 & \\
\hline L2-S1 & 22 & 10 & 12 & \\
\hline$>4$ levels, w/ L5-S1 & 31 & 16 & 15 & \\
\hline \multicolumn{5}{|l|}{ PCO at L5-S1 } \\
\hline Yes & 30 & 7 & 25 & \\
\hline No & 95 & 54 & 41 & \\
\hline Surgical time (mins) & $242.65 \pm 67.04$ & $251.48 \pm 67.04$ & $234.48 \pm 66.51$ & 0.154 \\
\hline Blood loss (ml) & $232.34 \pm 269.56$ & $387.92 \pm 310.40$ & $90.91 \pm 98.12$ & $<0.001$ \\
\hline Transfusion (ml) & $78.76 \pm 211.21$ & $154.90 \pm 285.71$ & $9.55 \pm 38.41$ & $<0.001$ \\
\hline Transfusion $(n=126)$ & & & & $<0.001$ \\
\hline No & 98 & 37 & 61 & \\
\hline Yes & 28 & 23 & 5 & \\
\hline Time to solid food (days) & $2.60 \pm 2.52$ & $4.03 \pm 2.55$ & $1.30 \pm 1.64$ & $<0.001$ \\
\hline Time to solid food & 126 & 60 & 66 & $<0.001$ \\
\hline 0 days & 32 & 3 & 29 & \\
\hline $1-3$ days & 52 & 24 & 28 & \\
\hline$>3$ days & 42 & 33 & 9 & \\
\hline Hospital stay (days) & $7.39 \pm 3.08$ & $7.79 \pm 3.46$ & $7.02 \pm 2.65$ & 0.159 \\
\hline Fusion rate & $268 / 343(78.1 \%)$ & $123 / 153(80.4 \%)$ & $145 / 190(76.3 \%)$ & 0.364 \\
\hline L2-3 & $25 / 27(92.6 \%)$ & $4 / 4(100 \%)$ & $21 / 23(91.3 \%)$ & \\
\hline L3-4 & $49 / 62(79.0 \%)$ & $24 / 27(88.9 \%)$ & $25 / 35(71.4 \%)$ & \\
\hline L4-5 & $94 / 127(74.0 \%)$ & $47 / 61(77.0 \%)$ & $47 / 66(71.2 \%)$ & \\
\hline L5-S1 & $100 / 127(78.7 \%)$ & $48 / 61(78.7 \%)$ & $52 / 66(78.8 \%)$ & \\
\hline Complications & & & & 0.108 \\
\hline No & 119 & 55 & 64 & \\
\hline Yes & 8 & 6 & 2 & \\
\hline \multicolumn{5}{|l|}{ Complications } \\
\hline lleus & & 2 & 2 & \\
\hline Acute kidney injury & & 1 & 0 & \\
\hline Bilateral iliopsoas weakness & & 1 & 0 & \\
\hline Abdominal wound hematoma & & 2 & 0 & \\
\hline
\end{tabular}

Values are presented as the number of patients (\%) or as the mean \pm SD. 
TABLE 2. Radiographic parameters of patients who did not undergo L5-S1 PCO

\begin{tabular}{lcccr}
\hline \multicolumn{1}{c}{ Variable } & Total $(\mathrm{n}=95)$ & ALIF $(\mathrm{n}=54)$ & OLIF $(\mathrm{n}=41)$ & p Value \\
\hline Mean cage height $(\mathrm{mm})$ & $14.35 \pm 1.93$ & $14.94 \pm 1.56$ & $13.56 \pm 2.11$ & 0.001 \\
\hline Mean cage lordosis $\left(^{\circ}\right)$ & $16.21 \pm 4.03$ & $15.87 \pm 4.23$ & $16.81 \pm 3.71$ & 0.278 \\
\hline Anterior disc height $(\mathrm{mm})$ & & & & \\
\hline Preop & $11.92 \pm 3.74$ & $11.53 \pm 3.46$ & $12.45 \pm 4.08$ & 0.234 \\
\hline Postop & $18.15 \pm 4.06$ & $18.87 \pm 3.82$ & $17.17 \pm 4.22$ & 0.043 \\
\hline Change & $6.22 \pm 3.87$ & $7.34 \pm 3.84$ & $4.72 \pm 3.41$ & 0.001 \\
\hline Posterior disc height $(\mathrm{mm})$ & & & & \\
\hline Preop & $5.65 \pm 2.02$ & $5.44 \pm 2.07$ & $5.93 \pm 1.95$ & 0.242 \\
\hline Postop & $8.09 \pm 2.61$ & $8.78 \pm 2.60$ & $7.17 \pm 2.36$ & 0.002 \\
\hline Change & $2.44 \pm 2.70$ & $3.35 \pm 2.87$ & $1.24 \pm 1.90$ & $<0.001$ \\
\hline L5-S1 segmental lordosis $\left(^{\circ}\right)$ & & & & \\
\hline Preop & $11.66 \pm 5.60$ & $11.52 \pm 5.76$ & $11.85 \pm 5.46$ & 0.775 \\
\hline Postop & $16.11 \pm 5.49$ & $15.85 \pm 5.74$ & $16.44 \pm 5.20$ & 0.608 \\
\hline Change & $4.44 \pm 5.60$ & $4.33 \pm 5.87$ & $4.59 \pm 5.29$ & 0.829 \\
\hline
\end{tabular}

Values are presented as the mean $\pm S D$.

$0.242)$. The mean postoperative posterior disc height was $8.78 \pm 2.60 \mathrm{~mm}$ for ALIF and $7.17 \pm 2.36 \mathrm{~mm}$ for OLIF $(\mathrm{p}=0.002)$. The mean increase in posterior disc height was $3.35 \pm 2.87 \mathrm{~mm}$ for ALIF and $1.24 \pm 1.90 \mathrm{~mm}$ for OLIF ( $\mathrm{p}<0.001)$. The mean preoperative L5-S1 segmental lordosis was $11.52^{\circ} \pm 5.76^{\circ}$ for ALIF and $11.85^{\circ} \pm 5.46^{\circ}$ for OLIF ( $\mathrm{p}=0.775)$. The mean postoperative L5-S1 segmental lordosis was $15.85^{\circ} \pm 5.74^{\circ}$ for ALIF and $16.44^{\circ} \pm$ $5.20^{\circ}$ for OLIF $(\mathrm{p}=0.608)$. The mean change in the L5-S1 segmental lordosis was $4.33^{\circ} \pm 5.87^{\circ}$ for ALIF and $4.59^{\circ} \pm$ $5.29^{\circ}$ for OLIF $(\mathrm{p}=0.829)$.

\section{Subgroup Analysis of Patients With L4-S1 Fusions}

As shown in Table 3, there were 34 patients (17 males, 17 females) who underwent L4-S1 ALIF and 31 patients who underwent L4-S1 OLIF. Age and sex were not different between the two groups. The mean surgical time was $233.53 \pm 72.56$ minutes for ALIF and $212.74 \pm 66.65$ minutes for OLIF $(\mathrm{p}=0.235)$. The mean blood loss for ALIF patients was $386.76 \pm 353.19 \mathrm{ml}$ and that for OLIF patients was $104.84 \pm 123.39 \mathrm{ml}(\mathrm{p}<0.001)$. The mean time to solid food intake was $3.18 \pm 1.78$ days for ALIF patients and $1.45 \pm 1.69$ days for OLIF patients $(\mathrm{p}<0.001)$. The average hospital stay was $6.56 \pm 2.904$ days for ALIF patients and $6.55 \pm 2.84$ days for OLIF patients $(\mathrm{p}=0.988)$.

There were 31 ALIF and 22 OLIF patients without L5S1 PCOs in the L4-S1 fusion subgroup. The mean cage height was $14.74 \pm 1.48 \mathrm{~mm}$ for ALIF patients and 13.68 $\pm 2.06 \mathrm{~mm}$ for OLIF patients $(\mathrm{p}=0.034)$, and the mean cage lordosis was $15.03^{\circ} \pm 4.66^{\circ}$ for the ALIF group and $16.70^{\circ} \pm 3.50^{\circ}$ for the OLIF group $(\mathrm{p}=0.069)$. The mean increase in anterior disc height was $7.25 \pm 4.22 \mathrm{~mm}$ for ALIF patients and $4.63 \pm 3.16 \mathrm{~mm}$ for OLIF patients $(\mathrm{p}=$ 0.019 ). The mean increase in posterior disc height was 3.37 $\pm 2.86 \mathrm{~mm}$ for ALIF patients and $1.16 \pm 1.88 \mathrm{~mm}$ for OLIF patients $(p=0.003)$. The mean change in L5-S1 segmental lordosis was $4.19^{\circ} \pm 6.13^{\circ}$ for ALIF patients and $4.41^{\circ} \pm$ $5.95^{\circ}$ for OLIF patients $(\mathrm{p}=0.899)$.

\section{Subgroup Analysis of Patients With L2-S1 and L3-S1 Fusions}

There were only 4 patients who underwent L2-S1 fusion, and these patients were combined with the L3-S1 fusion cohort (Table 4). There were 62 patients (ALIF 27, OLIF 35), and the mean age was $67.47 \pm 8.61$ years $(\mathrm{p}=$ 0.207). The mean follow-up was $27.15 \pm 6.96$ months for ALIF patients and $24.56 \pm 7.02$ months for OLIF patients $(\mathrm{p}=0.268)$. The mean surgical time for all patients was $262.60 \pm 57.84$ minutes, and there was no significant difference between ALIF and OLIF patients $(\mathrm{p}=0.172)$. The mean blood loss for ALIF and OLIF patients was $389.42 \pm$ $250.42 \mathrm{ml}$ and $78.57 \pm 68.10 \mathrm{ml}$, respectively $(\mathrm{p}<0.001)$. The mean transfusion volume for ALIF patients was $192.50 \pm 301.02 \mathrm{ml}$ and that for OLIF was $13.71 \pm 49.35$ $\mathrm{ml}(\mathrm{p}=0.006)$. The mean time to solid food intake was $5.07 \pm 2.97$ days for ALIF patients and $1.17 \pm 1.60$ days for OLIF patients $(\mathrm{p}<0.001)$. The mean hospital stay was $9.33 \pm 3.53$ days for ALIF patients and $7.43 \pm 2.43$ days for OLIF patients $(\mathrm{p}=0.015)$.

There were 23 ALIF and 19 OLIF patients who did not undergo L5-S1 PCOs in the L3-S1 and L2-S1 subgroups of patients. The mean cage height was $15.24 \pm 1.67 \mathrm{~mm}$ for ALIF and $13.41 \pm 2.24 \mathrm{~mm}$ for OLIF patients $(\mathrm{p}=$ $0.007)$, and the mean cage lordosis was $17.10^{\circ} \pm 3.22^{\circ}$ for the ALIF group and $16.24^{\circ} \pm 3.98^{\circ}$ for the OLIF group (p $=0.466$ ). The mean increase in anterior disc height was $7.46 \pm 3.35 \mathrm{~mm}$ for ALIF patients and $4.81 \pm 3.76 \mathrm{~mm}$ for OLIF patients $(\mathrm{p}=0.020)$. The mean increase in posterior disc height was $3.32 \pm 2.94 \mathrm{~mm}$ for ALIF and $1.34 \pm 1.97$ $\mathrm{mm}$ for OLIF ( $\mathrm{p}=0.017)$. The mean change in L5-S1 segmental lordosis was $4.52^{\circ} \pm 5.63^{\circ}$ for ALIF patients and $4.79^{\circ} \pm 4.57^{\circ}$ for OLIF patients $(\mathrm{p}=0.868)$.

\section{Discussion}

To our knowledge, this is the first report directly comparing multilevel OLIF and ALIF to the sacrum. ${ }^{8}$ Both 
TABLE 3. Perioperative parameters of patients who underwent ALIF and OLIF at L4-S1 only

\begin{tabular}{|c|c|c|c|c|}
\hline Variable & Total $(n=65)$ & ALIF $(n=34)$ & OLIF $(n=31)$ & $\mathrm{p}$ Value \\
\hline Age (yrs) & $60.17 \pm 11.51$ & $61.74 \pm 9.61$ & $58.45 \pm 13.24$ & 0.261 \\
\hline Sex & & & & 0.360 \\
\hline Male & 29 & 17 & 12 & \\
\hline Female & 36 & 17 & 19 & \\
\hline Follow-up time (mos) & $25.23 \pm 6.89$ & $27.26 \pm 6.87$ & $23.63 \pm 6.90$ & 0.245 \\
\hline Surgical time (mins) & $223.62 \pm 70.05$ & $233.53 \pm 72.56$ & $212.74 \pm 66.65$ & 0.235 \\
\hline Blood loss (ml) & $252.31 \pm 302.65$ & $386.76 \pm 353.19$ & $104.84 \pm 123.39$ & $<0.001$ \\
\hline Transfusion (ml) & $69.36 \pm 206.78$ & $126.15 \pm 274.47$ & $4.84 \pm 19.81$ & 0.015 \\
\hline Time to solid food (days) & $2.34 \pm 1.93$ & $3.18 \pm 1.78$ & $1.45 \pm 1.69$ & $<0.001$ \\
\hline Time to solid food & & 33 & 31 & 0.007 \\
\hline 0 days & 16 & 3 & 13 & \\
\hline $1-3$ days & 31 & 18 & 13 & \\
\hline$>3$ days & 17 & 12 & 5 & \\
\hline Hospital stay (days) & $6.55 \pm 2.85$ & $6.56 \pm 2.90$ & $6.55 \pm 2.84$ & 0.988 \\
\hline Radiographic Variables of L5-S1 (w/o L5-S1 PCO) & Total $(n=53)$ & $\operatorname{ALIF}(n=31)$ & OLIF $(n=22)$ & p Value \\
\hline Mean cage height (mm) & $14.3 \pm 1.80$ & $14.74 \pm 1.48$ & $13.68 \pm 2.06$ & 0.034 \\
\hline Mean cage lordosis $\left({ }^{\circ}\right)$ & $15.85 \pm 4.34$ & $15.03 \pm 4.66$ & $17.30 \pm 3.50$ & 0.069 \\
\hline \multicolumn{5}{|l|}{ Anterior disc height (mm) } \\
\hline Preop & $12.28 \pm 3.89$ & $11.87 \pm 3.65$ & $12.88 \pm 4.24$ & 0.364 \\
\hline Postop & $18.47 \pm 4.25$ & $19.12 \pm 4.33$ & $17.51 \pm 4.04$ & 0.184 \\
\hline Change & $6.19 \pm 4.01$ & $7.25 \pm 4.22$ & $4.63 \pm 3.16$ & 0.019 \\
\hline \multicolumn{5}{|l|}{ Posterior disc height (mm) } \\
\hline Preop & $5.86 \pm 2.12$ & $5.69 \pm 2.15$ & $6.10 \pm 2.10$ & 0.494 \\
\hline Postop & $8.31 \pm 2.83$ & $9.06 \pm 2.92$ & $7.26 \pm 2.36$ & 0.020 \\
\hline Change & $2.45 \pm 2.71$ & $3.37 \pm 2.86$ & $1.16 \pm 1.88$ & 0.003 \\
\hline \multicolumn{5}{|l|}{ L5-S1 segmental lordosis $\left({ }^{\circ}\right)$} \\
\hline Preop & $11.43 \pm 5.97$ & $11.19 \pm 5.90$ & $11.77 \pm 6.19$ & 0.731 \\
\hline Postop & $15.72 \pm 5.94$ & $15.39 \pm 6.04$ & $16.18 \pm 5.92$ & 0.636 \\
\hline Change & $4.28 \pm 6.00$ & $4.19 \pm 6.13$ & $4.41 \pm 5.95$ & 0.899 \\
\hline
\end{tabular}

Values are presented as the number of patients $(\%)$ or as the mean $\pm \mathrm{SD}$.

ALIF and LLIF can improve the height and lordosis of the disc space with an acceptable rate of complications. ${ }^{16}$ ALIF is generally easier to perform from L4 to S1 because of a single incision, while LLIF has historically been used to treat L2 to L5 because it is harder to access L2-3 via ALIF. ${ }^{1}$ When performing multilevel interbody fusions down to the sacrum, ALIF is often used because of its single incision and exposure of the entire spine. However, because of the minimally invasive approach and ease of access at L2-3 and L3-4, some surgeons have used LLIF in combination with ALIF at L5-S1, using two incisions and repositioning the patient. On the other hand, the L5-S1 OLIF allows access to the L5-S1 disc space in the lateral position. This not only affords concomitant access from L2 to L5, but it also obviates the need to reposition and re-drape the patient. ${ }^{11,17,18}$

With regard to previously published reports of OLIF complications, the overall complication rates have ranged from $4 \%$ to $15.5 \%$, and the ileus rates have ranged from $2.1 \%$ to $9.8 \% .^{9-11,19}$ With regard to previously published reports on ALIF, the overall complication rates have ranged from $9.61 \%$ to $26.47 \%$, and the ileus rates have ranged from $1.93 \%$ to $13.90 \% .{ }^{20,21}$ With regard to our study, our overall complication rates were comparable to previously published reports (3.03\% for OLIF and 9.84\% ALIF), and postoperative ileus rates were $3.03 \%$ for OLIF and $3.28 \%$ for ALIF. Because of the proximity to the iliac vessels, anterior surgery at L5-S1 has a higher risk of intraoperative vascular injury regardless of whether the procedure is an ALIF or OLIF approach. ${ }^{22,23}$ With regard to ileus rates after anterior surgery, it is thought that visceral manipulation results in temporary palsy and dysfunction of parasympathetic innervation of the abdominal viscera during ALIF and OLIF, leading to postoperative ileus colonic pseudo-obstruction. ${ }^{24,25}$ Thus, one reason that the OLIF patients may have had a quicker recovery time from ileus is less dissection and manipulation of the abdominal viscera. With regard to the observation that ALIF had longer times between stages than OLIF, if a patient had severe abdominal distension secondary to ileus, the second stage may have been postponed until the patient recovered from the ileus. This would have resulted in delay in the second 
TABLE 4. Perioperative parameters of patients who underwent ALIF and OLIF at L2-S1

\begin{tabular}{|c|c|c|c|c|}
\hline Variable & Total $(n=62)$ & ALIF $(n=27)$ & OLIF $(n=35)$ & $\mathrm{p}$ Value \\
\hline Age & $67.47 \pm 8.61$ & $63.89 \pm 9.79$ & $68.69 \pm 7.49$ & 0.207 \\
\hline Sex & & & & 0.822 \\
\hline Male & 22 & 10 & 12 & \\
\hline Female & 40 & 17 & 23 & \\
\hline Follow-up time (mos) & $26.05 \pm 6.99$ & $27.15 \pm 6.96$ & $24.56 \pm 7.02$ & 0.268 \\
\hline Surgical time (mins) & $262.60 \pm 57.84$ & $274.07 \pm 52.31$ & $253.74 \pm 61.02$ & 0.172 \\
\hline Blood loss (ml) & $211.07 \pm 229.74$ & $389.42 \pm 250.42$ & $78.57 \pm 68.10$ & $<0.001$ \\
\hline Transfusion (ml) & $89.92 \pm 216.98$ & $192.50 \pm 301.02$ & $13.71 \pm 49.35$ & 0.006 \\
\hline Time to solid food (days) & $2.87 \pm 3.00$ & $5.07 \pm 2.97$ & $1.17 \pm 1.60$ & $<0.001$ \\
\hline Time to solid food & & & & $<0.001$ \\
\hline 0 days & 16 & 0 & 16 & \\
\hline $1-3$ days & 21 & 6 & 15 & \\
\hline$>3$ days & 25 & 21 & 4 & \\
\hline Hospital stay (days) & $8.26 \pm 3.08$ & $9.33 \pm 3.53$ & $7.43 \pm 2.43$ & 0.015 \\
\hline Radiographic Variables at L5-S1 (w/o L5-S1 PCO) & Total $(n=42)$ & $\operatorname{ALIF}(n=23)$ & OLIF $(n=19)$ & $\mathrm{p}$ Value \\
\hline Mean cage height (mm) & $14.42 \pm 2.13$ & $15.24 \pm 1.67$ & $13.41 \pm 2.24$ & 0.007 \\
\hline Mean cage lordosis $\left(^{\circ}\right)$ & $16.71 \pm 3.56$ & $17.10 \pm 3.22$ & $16.24 \pm 3.98$ & 0.466 \\
\hline \multicolumn{5}{|l|}{ Anterior disc height (mm) } \\
\hline Preop & $11.48 \pm 3.54$ & $11.08 \pm 3.20$ & $11.97 \pm 3.95$ & 0.422 \\
\hline Postop & $17.74 \pm 3.83$ & $18.54 \pm 3.06$ & $16.78 \pm 4.50$ & 0.140 \\
\hline Change & $6.26 \pm 3.74$ & $7.46 \pm 3.35$ & $4.81 \pm 3.76$ & 0.020 \\
\hline \multicolumn{5}{|l|}{ Posterior disc height (mm) } \\
\hline Preop & $5.38 \pm 1.89$ & $5.09 \pm 1.95$ & $5.73 \pm 1.79$ & 0.281 \\
\hline Postop & $7.80 \pm 2.32$ & $8.41 \pm 2.09$ & $7.07 \pm 2.42$ & 0.061 \\
\hline Change & $2.42 \pm 2.71$ & $3.32 \pm 2.94$ & $1.34 \pm 1.97$ & 0.017 \\
\hline \multicolumn{5}{|l|}{ L5-S1 segmental lordosis $\left({ }^{\circ}\right)$} \\
\hline Preop & $11.95 \pm 5.17$ & $11.96 \pm 5.68$ & $11.95 \pm 4.62$ & 0.996 \\
\hline Postop & $16.60 \pm 4.88$ & $16.48 \pm 5.38$ & $16.74 \pm 4.36$ & 0.867 \\
\hline Change & $4.64 \pm 5.12$ & $4.52 \pm 5.63$ & $4.79 \pm 4.57$ & 0.868 \\
\hline
\end{tabular}

Values are presented as the number of patients (\%) or as the mean \pm SD.

stage, and because ALIF had a higher rate of ileus, this may have partially accounted for our observation. With regard to the reasons that ALIF had longer times than OLIF to solid food intake, there are probably 2 main reasons for this observation. First is that there is less bowel retraction and manipulation of the parasympathetic plexus in OLIF, not only because the OLIF approach is off to one side, but also because the abdominal contents have shifted to the contralateral side, requiring less retraction and manipulation to access the disc space. Second, ALIF patients did have a higher rate of ileus, and these outliers probably skewed the mean time to solid food intake.

With regard to radiographic analysis of the L5-S1 segment, we excluded patients with PCOs because osteotomies can affect lordosis and disc height (through posterior release). Even though patients who had L5-S1 PCOs were excluded from the radiographic assessment, they were included in the clinical assessment of approach-related morbidity and complications. After excluding L5-S1 PCO cases, the mean L5-S1 cage height for ALIF patients $(14.94 \mathrm{~mm})$ was higher than that for OLIF patients $(13.56$ $\mathrm{mm})(\mathrm{p}=0.001)$. We found that placing larger cages with L5-S1 in ALIF procedures also had better restoration of anterior and posterior disc height. Because radiographic measurements at L5-S1 were in a lordotic segment, the mean cage height $(15 \mathrm{~mm})$ was smaller than the mean anterior disc height $(18 \mathrm{~mm})$ but larger than the mean posterior disc height $(8 \mathrm{~mm})$. However, the lordosis of L5-S1 cages was similar between ALIF and OLIF groups $\left(15.87^{\circ}\right.$ and $16.81^{\circ}$, respectively; $\mathrm{p}=0.278$ ) and the increase of lordosis at L5-S1 was similar between the two groups. Thus, our results showed that although there was no significant difference in segmental lordosis at L5-S1 between ALIF and OLIF, there was better disc height restoration with ALIF.

There are limitations to this study. First, this is a singleinstitution retrospective series. Second, although the mean follow-up times for ALIF and OLIF groups were 27.21 and 24.11 months, respectively, a minimum 2-year followup for all patients would have been ideal for a rigorous study. Third, this article did not compare the functional outcomes and subsidence rates, mainly because reports have shown that subsidence rates and functional outcomes 
in both LLIF and OLIF are comparable to those in ALIF. ${ }^{26}$ Fourth, although there was no difference in hospital stay, this may not be an accurate number because of the variability of the posterior surgery. If a patient had undergone L3-S1 surgery compared to T3-S1 surgery, their hospital stay could have been profoundly affected, but we were not able to control for this. However, since we focused on the perioperative factors of the anterior approach alone (ileus, anterior-only blood loss, and disc height only at L5-S1), this should have been less of a factor in terms of assessing the differences in the ALIF and OLIF approaches. Nonetheless, despite these limitations, we believe that the uniqueness of this direct comparison may be useful to help surgeons understand the pros and cons of each approach when contemplating multilevel interbody fusions to the sacrum.

\section{Conclusions}

Patients who underwent multilevel OLIF to the sacrum appear to have comparable operative times and hospital stays to those who underwent ALIF. ALIF afforded larger cage placement at L5-S1, resulting in better disc height restoration but comparable lordosis induction with OLIF. OLIF had less blood loss, and there may be faster recovery from postoperative ileus after OLIF owing to less bowel manipulation than is required in ALIF.

\section{Acknowledgments}

Dr. Chang received funding from Yen Tjing Ling Medical Foundation, a nongovernment foundation that has no association with any implant or with the pharmaceutical industry.

\section{References}

1. Mobbs RJ, Phan K, Malham G, et al. Lumbar interbody fusion: techniques, indications and comparison of interbody fusion options including PLIF, TLIF, MI-TLIF, OLIF/ATP, LLIF and ALIF. J Spine Surg. 2015;1(1):2-18.

2. Phan K, Thayaparan GK, Mobbs RJ. Anterior lumbar interbody fusion versus transforaminal lumbar interbody fusion-systematic review and meta-analysis. $\mathrm{Br} J$ Neurosurg. 2015;29(5):705-711.

3. Mobbs RJ, Phan K, Daly D, et al. Approach-related complications of anterior lumbar interbody fusion: results of a combined spine and vascular surgical team. Global Spine J. 2016;6(2):147-154

4. Dorward IG, Lenke LG, Bridwell KH, et al. Transforaminal versus anterior lumbar interbody fusion in long deformity constructs: a matched cohort analysis. Spine (Phila Pa 1976). 2013;38(12):E755-E762.

5. Schroeder GD, Kepler CK, Millhouse PW, et al. L5/S1 fusion rates in degenerative spine surgery: a systematic review comparing ALIF, TLIF, and axial interbody arthrodesis. Clin Spine Surg. 2016;29(4):150-155.

6. Pinson H, Hallaert G, Herregodts P, et al. Outcome of anterior lumbar interbody fusion: a retrospective study of clinical and radiologic parameters. World Neurosurg. 2017;103:772-779.

7. Ajiboye RM, Alas H, Mosich GM, et al. Radiographic and clinical outcomes of anterior and transforaminal lumbar interbody fusions: a systematic review and meta-analysis of comparative studies. Clin Spine Surg. 2018;31(4):E230-E238.

8. Lee CS, Park SJ, Chung SS, et al. Mini-open anterior lumbar interbody fusion combined with lateral lumbar interbody fusion in corrective surgery for adult spinal deformity. Asian Spine J. 2016;10(6):1023-1032.

9. Quillo-Olvera J, Lin GX, Jo HJ, Kim JS. Complications on minimally invasive oblique lumbar interbody fusion at L2-L5 levels: a review of the literature and surgical strategies. Ann Transl Med. 2018;6(6):101.

10. Xu DS, Walker CT, Godzik J, et al. Minimally invasive anterior, lateral, and oblique lumbar interbody fusion: a literature review. Ann Transl Med. 2018;6(6):104.

11. Woods KR, Billys JB, Hynes RA. Technical description of oblique lateral interbody fusion at L1-L5 (OLIF25) and at L5-S1 (OLIF51) and evaluation of complication and fusion rates. Spine J. 2017;17(4):545-553.

12. Tropiano P, Giorgi H, Faure A, Blondel B. Surgical techniques for lumbo-sacral fusion. Orthop Traumatol Surg Res. 2017;103(1S):S151-S159.

13. Mobbs RJ, Phan K, Assem Y, et al. Combination Ti/PEEK ALIF cage for anterior lumbar interbody fusion: early clinical and radiological results. J Clin Neurosci. 2016;34:9499.

14. Kim DB, Shin MH, Kim JT. Vertebral body rotation in patients with lumbar degenerative scoliosis: surgical implication for oblique lumbar interbody fusion. World Neurosurg. 2019;124:e226-e232.

15. DiGiorgio AM, Edwards CS, Virk MS, et al. Stereotactic navigation for the prepsoas oblique lateral lumbar interbody fusion: technical note and case series. Neurosurg Focus. 2017;43(2):E14.

16. Ohtori S, Orita S, Yamauchi K, et al. Mini-open anterior retroperitoneal lumbar interbody fusion: oblique lateral interbody fusion for lumbar spinal degeneration disease. Yonsei Med J. 2015;56(4):1051-1059.

17. Silvestre C, Mac-Thiong JM, Hilmi R, Roussouly P. Complications and morbidities of mini-open anterior retroperitoneal lumbar interbody fusion: oblique lumbar interbody fusion in 179 patients. Asian Spine J. 2012;6(2):8997.

18. Zairi F, Sunna TP, Westwick HJ, et al. Mini-open oblique lumbar interbody fusion (OLIF) approach for multi-level discectomy and fusion involving L5-S1: preliminary experience. Orthop Traumatol Surg Res. 2017;103(2):295299.

19. Phan K, Maharaj M, Assem Y, Mobbs RJ. Review of early clinical results and complications associated with oblique lumbar interbody fusion (OLIF). J Clin Neurosci. 2016;31:23-29.

20. Phan K, Xu J, Scherman DB, et al. Anterior lumbar interbody fusion with and without an "access surgeon": a systematic review and meta-analysis. Spine (Phila Pa 1976). 2017;42(10):E592-E601.

21. Härtl R, Joeris A, McGuire RA. Comparison of the safety outcomes between two surgical approaches for anterior lumbar fusion surgery: anterior lumbar interbody fusion (ALIF) and extreme lateral interbody fusion (ELIF). Eur Spine J. 2016;25(5):1484-1521.

22. Liu L, Liang $Y$, Zhang $H$, et al. Imaging anatomical research on the operative windows of oblique lumbar interbody fusion. PLoS One. 2016;11(9):e0163452.

23. Chung NS, Jeon CH, Lee HD, Kweon HJ. Preoperative evaluation of left common iliac vein in oblique lateral interbody fusion at L5-S1. Eur Spine J. 2017;26(11):27972803.

24. Wang $\mathrm{K}$, Zhang $\mathrm{C}, \mathrm{Wu} \mathrm{H}$, et al. The anatomic characteristics of the retroperitoneal oblique corridor to the L1-S1 intervertebral disc spaces. Spine (Phila Pa 1976). 2019;44(12):E697-E706.

25. Than KD, Wang AC, Rahman SU, et al. Complication avoidance and management in anterior lumbar interbody fusion. Neurosurg Focus. 2011;31(4):E6. 
26. Hah R, Kang HP. Lateral and oblique lumbar interbody fusion-current concepts and a review of recent literature. Curr Rev Musculoskelet Med. 2019;12:305-310.

\section{Disclosures}

Dr. Chou reports being a consultant for Globus and Medtronic; he receives royalties from Globus. Dr. Mummaneni reports being a consultant for DePuy Synthes, Globus, and Stryker; he owns stock in Spinicity/ISD; he receives royalties from DePuy Synthes, Thieme Publishers, and Springer Publishing; and he receives support of non-study-related clinical or research efforts that he oversees from the following: AO Spine, NREF, and ISSG. Dr. Eichler reports being a consultant for Medtronic and NuVasive. Dr. Burch reports being a consultant for Medtronic and Zimmer Biomet.

\section{Author Contributions}

Conception and design: Xi. Acquisition of data: Xi, Eichler. Analysis and interpretation of data: Xi. Drafting the article: Xi.

Critically revising the article: Chou, Mummaneni. Reviewed sub- mitted version of manuscript: Chou, Mummaneni, Chang, Burch. Statistical analysis: Chou. Administrative/technical/material support: Mummaneni, Ruan, Chang, Burch.

\section{Supplemental Information}

Online-Only Content

Supplemental material is available with the online version of the article.

Supplemental Table 1. https://thejns.org/doi/suppl/10.3171/ 2020.4.SPINE20198.

\section{Correspondence}

Zhuo Xi: University of California, San Francisco, CA. neurosurgeon-xz@hotmail.com. 